\title{
CONDENAÇÕES DA GOOGLE PELA APLICAÇÃO DO DIREITO DA CONCORRÊNCIA DA UNIÃO EUROPEIA
}

Google condemnations by the application of European Union competition law

Pablo Leurquin ${ }^{1}$

Lucas Anjos ${ }^{2}$

\section{RESUMO}

A Google tem sido investigada em diversos países por práticas anticoncorrenciais. Entretanto, não é comum que a mesma seja punida nesses processos. As recentes condenações da Google na União Europeia chamam, portanto, atenção. O objetivo deste artigo é analisar a aplicação do Direito da Concorrência da União Europeia nos casos envolvendo a Google. Para tanto, foi realizada pesquisa bibliográfica, na literatura jurídica e econômica, com a finalidade de compreender seu modelo de negócio e como esses julgados se inserem no movimento de modernização do Direito da União Europeia. Além disso, foi realizada pesquisa documental na jurisprudência europeia, com intuito de elucidar os argumentos empregados pelas autoridades europeias na condenação da Google em três casos distintos, a saber, Google Shopping, Google-Android e Google Adsense. Foi possivel constatar que o modelo europeu oferece contribuições originais para se pensar em uma função reguladora da inovação pela aplicação do Direito da Concorrência.

Palavras-chave: Google; Direito da União Europeia; Direito da Concorrência; Direito Econômico.

\begin{abstract}
Google has been investigated in several countries for anti-competitive practices. However, it is not common for it to be condemned in these processes. Google's recent condemnations in the European Union are therefore noteworthy. The purpose of this article is to analyze the application of European Union competition law in cases involving Google. To this end, bibliographic research was carried
\end{abstract}

1 Doutor em Direito pela Université Paris 1 Panthéon-Sorbonne e pela Universidade Federal de Minas Gerais, em cotutela. Mestre em Direito pela Universidade Federal de Minas Gerais. Bacharel em Direito pela Universidade Federal do Rio Grande do Norte. Professor Adjunto da Universidade Federal de Juiz de Fora - campus Governador Valadares. Líder do Centro de Pesquisa em Direito Econômico (CPDE-UFJF/GV) e do Centro de Estudos em Pensamento Político (CEPP-UFJF/GV). E-mail: pabloleurquin@gmail.com

2 Doutorando em Direito pela Université libre de Bruxelles e pela Universidade Federal de Minas Gerais, em cotutela. Mestre e Bacharel em Direito pela Universidade Federal de Minas Gerais. Professor Assistente da Universidade Federal de Juiz de Fora - campus Governador Valadares. Coordenador do Grupo de Estudos em Tecnologia e Sociedade (GETS-UFJF/GV), membro do JurisLab (FabLab ULB e Centre de Droit Privé) e conselheiro científico do Instituto de Referência em Internet e Sociedade (IRIS). E-mail: lucascostaanjos@gmail.com 
out in the legal and economic literature, with the aim of understanding its business model and how these judgments fit into the European Union Law modernization movement. In addition, documentary research was carried out in European jurisprudence, in order to elucidate the arguments used by European authorities in condemning Google in three different cases, namely, Google Shopping, Google-Android and Google Adsense. It was possible to verify that the European model offers original contributions to think about a regulatory function of innovation through the application of Competition Law.

Keywords: Google, European Union law; Competition law; Economic law

Sumário: 1. Introdução; 2. Contexto das condenações da Google: um olhar a partir do seu modelo de negócio; 2.1 Modelo de negócio da Google; 2.2 Modernização do Direito da Concorrência da União Europeia; 3. Condenação no caso Google Shopping; 4. Condenação no caso Google-Android; 5. Condenação no caso Google Adsense; 6. Conclusão; Referências.

\section{INTRODUÇÃO}

Segundo estatísticas mais recentes, a Google ocupa o primeiro lugar na concorrência entre mecanismos de busca em termos globais (88\%) (THE 100 LARGEST..., 2020) e detém mais de 90\% desse mercado nos Estados-membros da União Europeia (ANTITRUST..., 2019). Além disso, 35\% das buscas por produtos online começam no mecanismo de busca da Google ${ }^{3}$, sendo que a empresa (Alphabet Inc.) ocupa o 5 o lugar mundial entre as companhias de maior valor (US\$ 919,3 bilhões) (THE 100 LARGEST..., 2020).

Em uma sociedade cada vez mais digitalizada, com crescente migração para cadeias de produção digital de valor, essas estatísticas tornam-se relevantes não apenas para empresas que visam a ofertar seus produtos e serviços online, como também para órgãos de regulação e monitoramento de mercado, como a Comissão Europeia. No início dos anos 2010, o órgão europeu iniciou intenso escrutínio concorrencial das atividades da Google, denunciadas como anticompetitivas por alguns de seus concorrentes em diversos setores. É importante notar que a própria pandemia provocada pelo Covid-19 acelerou algumas tendências de concentração em mercados da economia digital (ANG, 2020), o que torna essas análises de práticas anticompetitivas ainda mais relevantes e necessárias para o bom funcionamento desses mercados.

Além disso, a União Europeia também buscou opções regulatórias ex ante para mecanismos de busca e de intermediação de serviços online, como o da Google, por meio do Regulamento n. 1150, de 2019, e das Diretrizes da Comissão Europeia sobre a Transparência de Rankings de acordo com o Regulamento n. 1150, publicadas em Dezembro de 2020. Portanto, o mecanismo de busca da Google está no centro das discussões concorrenciais há, pelo menos, uma década, sejam elas no âmbito do Direito da Concorrência, sejam elas por meio da regulação setorial.

3 De acordo com Sterling (2016): “Entre os 35 por cento dos compradores que começaram na Google, 52\% disseram que clicaram nos resultados do Google Shopping, $41 \%$ clicaram em um link da Amazon e um número semelhante clicou em um link de varejista, enquanto $27 \%$ clicaram em sites de marcas." (tradução livre). 
Nos Estados Unidos, em Outubro de 2020, o Departamento de Justiça ajuizou procedimento antitruste contra a Google por "manter monopólios ilegalmente por meio de práticas anticompetitivas e de exclusão nos mercados de busca e de publicidade em mecanismos de busca e para remediar os danos à concorrência." ${ }^{\prime 4}$ Os fundamentos do processo são bastante similares àqueles dos casos europeus, ${ }^{5}$ o que denota não apenas a importância da experiência da União Europeia na regulação das práticas anticompetitivas no meio digital, como também revela tendência que pode ser replicada por outras autoridades da concorrência em jurisdições diversas, como a brasileira.

O processo foi apoiado por vários procuradores-gerais estaduais estadunidenses e revela uma mudança substancial em relação à última década, em que as autoridades legislativas e executivas americanas foram bastante lenientes com empresas de tecnologia, como Google e Facebook, especialmente no que diz respeito a seus comportamentos anticompetitivos. ${ }^{6}$ Isso pode sugerir mudanças em um futuro próximo, não apenas das políticas regulatórias, mas também das políticas da empresa em relação a novas aquisições (KANG; MCCABE; WAKABATASHI, 2020).

No Brasil, por sua vez, três investigações contra a Google estão em curso no Cade. A primeira delas é sobre a legalidade do comportamento da empresa ao encorajar os fabricantes de smartphones a pré-instalar seus aplicativos e serviços nos dispositivos que funcionam com o sistema Android (VALENTE, 2019). A segunda delas é sobre a atuação da Google no mercado de notícias, dada a suspeita que a empresa tenha copiado parte do conteúdo de sites jornalísticos no resultado das pesquisas, desestimulando o acesso aos sites concorrentes (BRASIL, 2019). A terceira delas é sobre a possibilidade da Google utilizar o seu poder de mercado para prejudicar a Yelp por prejudicar o referido site de avaliações no Brasil (BRASIL, 2016).

Além desses casos, o Cade já arquivou outros processos contra a Google. O primeiro deles foi sobre a autopromoção do Google Shopping em detrimento de outros comparadores de preço, em um argumento bastante similar ao do caso homônimo europeu. O segundo foi o suposto plágio de avaliações feitas por consumidores de outros sites. O terceiro foi derivado de denúncia da Microsoft, que acusou a Google de criar dificuldades para que empresas anunciassem ao mesmo tempo em outras páginas de resultados de busca (RODRIGUES, 2020).

$4 \quad$ Tradução livre de: “Today, the Department of Justice - along with eleven state Attorneys General - filed a civil antitrust lawsuit in the U.S. District Court for the District of Columbia to stop Google from unlawfully maintaining monopolies through anticompetitive and exclusionary practices in the search and search advertising markets and to remedy the competitive harms." (ESTADOS UNIDOS, 2020).

5 Entre as acusações do DOJ americano, estão: a celebração de acordos de exclusividade que proíbem a pré-instalação de qualquer serviço de busca concorrente; a celebração de acordos que forçam a pré-instalação de seus aplicativos de pesquisa em localizações privilegiadas em dispositivos móveis e os torna impossíveis de excluir, independentemente da preferência do consumidor; a celebração de contratos de longo prazo com a Apple que exigem que a Google seja o padrão - e de fato exclusivo - mecanismo de pesquisa geral no navegador Safari e outras ferramentas de pesquisa da Apple; a utilização de lucros de monopólio para comprar tratamento preferencial para seu mecanismo de pesquisa em dispositivos, navegadores da web e outros pontos de acesso de pesquisa, criando um ciclo contínuo e auto-reforçado de monopolização. (ESTADOS UNIDOS, 2020).

6 Um dos casos mais significativos de ação antitruste contra empresas de tecnologia nos Estados Unidos desde o caso contra a Microsoft, em 1997, a ação contra a Google também se inspira nesse passado. Segundo Scott Galloway, "este é um eco do caso DOJ contra a Microsoft. E o DOJ, que inicialmente teve sucesso contra a Microsoft, disse que a Microsoft estava usando o poder de agrupamento de produtos (bundling) e poder econômico para forçar todos os fabricantes de hardware de computador a agrupar o Internet Explorer", em tradução livre (WALSH, 2020). 
Essa sucinta síntese das investigações de órgãos de defesa da concorrência no Brasil, União Europeia e Estados Unidos permite compreender que a aplicação desse ramo do Direito tem sido um campo de disputa sobre a definição de qual modelo deve ser adotado. Em outras palavras, questiona-se se autoridades da concorrência devem ser mais permissivas com as condutas de empresas em posição dominante, como a Google, ou não. 0 objetivo deste artigo se insere nesse contexto. Pretende-se analisar os argumentos empregados pelas autoridades europeias para punir a Google por meio da aplicação do Direito da Concorrência da União Europeia. Para tanto, o trabalho foi dividido em três seções.

Na primeira seção, será avaliado o contexto em que as condenações da Google na União Europeia estão inseridas, enfatizando como as preocupações com o modelo de negócio da Google são, em alguma medida, decorrentes da modernização do Direito da Concorrência da União Europeia. Nas segunda, terceira e quarta seções, serão analisadas as três condenações contra a Google, todas relacionadas de certa forma a seu mecanismo de busca. Serão apresentados, respectivamente, o caso Google Shopping, acerca de sua ferramenta vertical de comparação de preços; o caso Android, acerca da preferência e exclusividade dada aos mecanismos de busca e navegação da Google em sistemas operacionais criados pela empresa; e o caso AdSense, acerca da análise de cláusulas contratuais abusivas na intermediação de anúncios publicitários em mecanismos de busca gerenciados pela Google em sites de terceiros.

\section{CONTEXTO DAS CONDENAÇÕES DA GOOGLE: UM OLHAR A PARTIR DE SEU MODELO DE NEGÓCIO}

\subsection{Modelo de negócio da Google}

O modelo de negócio da Google foi o embrião para uma série de empreendimentos bem-sucedidos do Vale do Silício e, atualmente, inspira startups em diversas partes do mundo. As consultas de pesquisa da Google produzem "dados colaterais", além das palavras-chave inicialmente digitadas na barra de pesquisa. Atualmente, o processo leva em consideração "o número e o padrão dos termos de pesquisa, como uma consulta é formulada, ortografia, pontuação, tempos de permanência, padrões de clique e localização" (ZUBOFF, 2019, p. 67).

Além disso, são empregados dados pessoais como geolocalização do dispositivo (computador, celular, tablet), histórico de pesquisas pregressas, termos utilizados com frequência em outras aplicações da Google (YouTube, Gmail, Maps etc.) e o histórico de navegação online, especialmente se utilizado o navegador da Google, o Chrome. A princípio, essas informações adicionais, que Zuboff (2019, p. 69) chama de "excedente comportamental", são reinvestidas na melhoria da plataforma e no aperfeiçoamento do seu mecanismo de busca. As informações sobre os padrões de pesquisa dos usuários e seu histórico de resultados de navegação são utilizadas para corrigir imperfeições e melhorar o serviço.

Além dos resultados referentes à pesquisa de palavras-chave, são exibidos anúncios publicitários pagos no topo da lista de resultados. Em vez de direcionar seus usuários para a exibição de anúncios relacionados apenas às consultas de pesquisa (palavras-chave), a Google passou a usar todas as informações coletadas de seus usuários para melhorar a qualidade desses anúncios (ZUBOFF, 
2019). Com sua capacidade cada vez maior de prever as preferências dos usuários por meio de um crescente número de pessoas utilizando suas plataformas, a Google criou o AdWords.

A ideia por trás do Google AdWords (que mais tarde se tornaria simplesmente "Google Ads") era fornecer uma correspondência perfeitamente adaptada entre os anúncios pagos (normalmente encaminhando usuários à página de seu produto ou serviço) e os perfis individuais dos usuários. o preço do anúncio variaria de acordo com sua posição na página de resultados de pesquisa e o número de cliques derivados desse anúncio em um sistema baseado em leilão, o que acontecia de maneira muito rápida e eficiente?

Enquanto outros motores de busca basearam sua publicidade direcionada nas palavras-chave enviadas e no número médio de usuários acessando a plataforma, a Google concebeu uma forma de venda de espaço publicitário que também incentivou a competição por uma alocação mais favorável de seus recursos de publicidade. Em tese, a corretagem de anúncios pela Google é mais eficiente e menos custosa para anunciantes, pois baseia-se na competição entre os lances de competidores, e não na fixação unilateral de preços pela Google, além de perfilar exatamente o público que visa a atingir.

Essa estratégia aumentou significativamente o número de usuários encaminhados para os anunciantes, bem como o valor inerente dos canais de publicidade da empresa no mercado e, como consequência, sua receita. Do ponto de vista publicitário, a capacidade de atingir um público com base não apenas em suposições acerca de faixas etárias e localização (local, nacional ou internacional, conforme revelado pela geolocalização), mas também em seus dados pessoais e padrões de navegação pregressa (graças à coleção de cookies que podem informar a personalização de anúncios) permitem a forma ideal de marketing (CHRISTENSSON, 2011).

Com a tendência crescente de geração de dados de todos os tipos de fontes, inclusive aqueles gerados offline, a publicidade pode se tornar ainda mais individualizada no futuro ${ }^{8}$. As abordagens para fazer isso incluem métodos de segmentação conhecidos como "segmentação granular" e "segmentação de cauda longa", com os quais as necessidades de cada indivíduo da curva de demanda podem ser melhor atendidas de acordo com suas necessidades personalizadas e sob medida. Basicamente, este é o sonho de todo publicitário: a capacidade de atingir precisamente as pessoas que estão a um passo de comprar o que estão tentando vender, de forma individualizada.

De acordo com Zuboff (2019, p. 150), essa foi uma estratégia de negócios crucial para o sucesso da Google, que fez uso inteligente de seu acesso exclusivo ao comportamento do usuário, não apenas para melhorar o aplicativo do mecanismo de pesquisa, mas também para criar uma fonte de receita extremamente lucrativa para a empresa. A receita de vigilância é então reinvestida não apenas em tecnologia preditiva mais inteligente, mas também em outros aplicativos sob o guarda-chuva

7 De acordo com Peter Coy (2006): “A Google maximiza a receita que obtém desse precioso ativo, dando sua melhor posição ao anunciante que provavelmente pagará mais à Google no total, com base no preço por clique multiplicado pela estimativa da Google da probabilidade de alguém realmente clicar no anúncio" (tradução livre).

8 Segundo Sandra Wachter (2019, p. 150): “Os serviços digitais e dispositivos distribuídos agora operam cada vez mais em uma base interligada, em que as informações são compartilhadas entre redes de dispositivos e provedores de serviços, fazendo uso de identificadores de usuário exclusivos para fornecer compartilhamento de dados contínuo e experiências personalizadas usando aprendizado de máquina e IA". 
da Alphabet Inc., a fim de multiplicar as fontes e oportunidades de coleta de dados exclusivos dos usuários9. Empresas como Facebook e Twitter aplicam lógica bastante similar, já que ofertam serviços gratuitos a usuários finais, inclusive em plataformas secundárias, como Instagram e WhatsApp, mas monetizam suas atividades a partir de dados pessoais que são recolhidos e aplicados de forma transversal.

A importância das investigações, dos argumentos empregados, das multas e dos ajustes de conduta aplicados no contexto da União Europeia para outras jurisdições só pode ser compreendida se o tema for analisado sob a luz do processo de modernização do Direito da Concorrência da União Europeia, sobretudo, no eixo das práticas unilaterais.

\subsection{Modernização do Direito da Concorrência da União Europeia}

A importância do domínio dos abusos de posição dominante, chamados atualmente de práticas unilaterais, é uma das principais características do Direito da Concorrência da União Europeia, principalmente se comparada à tradição estadunidense. Entretanto, esse eixo da política europeia de concorrência foi sempre muito criticado por causa de sua denotação formalista, considerada muitas vezes como uma simples aplicação do método de ilicitude per se (PRIETO; BOSCO, 2013).

Com intuito de responder às críticas ao modelo europeu, deu-se início a um processo de modernização na legislação do Direito da Concorrência da União Europeia. O referido movimento começou no domínio dos acordos anticoncorrenciais, consubstanciado no Regulamento n. 1/2003. Já no domínio das práticas unilaterais, ocorreu apenas em 2009. Importa frisar que as condenações da Google se inserem nesse segundo eixo de aplicação do Direito da Concorrência da União Europeia. Por essa razão, este trabalho vai se deter ao mesmo (LEURQUIN, 2018).

A reforma de 2009 só pode ser compreendida a partir do julgamento do caso Microsoft, na medida em que representa a aplicação de uma análise fundada sob os efeitos no domínio do abuso de posição dominante, que é elemento central da reforma de 2009. Além disso, essa decisão pode ser interpretada como uma síntese da oposição entre a tradição estadunidense e a europeia, no que diz respeito à importância desse eixo do Direito da Concorrência nos mercados de alta tecnologia (PRIETO, 2004).

As orientações de 2009 da Comissão para aplicação do art. 82, do Tratado das Comunidades Europeias (atual art. 102, do TFUE)(UNIÃO EUROPEIA, 2016), têm por objetivo tornar mais claro e previsível o quadro geral de análise, sem perder de vista a necessidade de uma intervenção mais eficaz. De acordo com as orientações:

A intervenção da Comissão no âmbito dos comportamentos de exclusão tem sobretudo em vista a salvaguarda da concorrência no mercado interno e a garantia de que as empresas que detêm uma posição dominante não ex-

9 De acordo com Evgeny Morozov (2018, p. 151), a empresa inclusive superou seu modelo de negócios inicial, se aventurando hodiernamente em outras aplicações e diversificando suas fontes de receita: “Há um equívoco em enxergá-la [a Google] como uma empresa atuante no mercado de buscas ou no da publicidade; na verdade, seu negócio são informações preditivas, e há muitas outras maneiras de rentabilizá-las sem a necessidade de recorrer à publicidade ou aos resultados de buscas para saber de quais informações necessitamos". 
cluirão os seus rivais através de outros meios que não sejam a concorrência com base no mérito dos bens ou serviços que fornecem. Neste contexto, a Comissão reconhece que o mais importante é a protecção de um verdadeiro processo de concorrência e não a mera protecção dos concorrentes. Isso poderá significar que os concorrentes que tenham um desempenho inferior para os consumidores em termos de preço, gama da oferta, qualidade e inovação poderão desaparecer do mercado (COMISSÃO EUROPEIA, 2009).

A normatização da ilicitude de comportamentos de empresas dominantes que pretendem excluir seus concorrentes é uma das mais importantes contribuições do Direito Europeu. A sua construção decorre principalmente da definição de uma responsabilidade da empresa em posição dominante com a própria dinâmica de mercado. Essa responsabilidade especial restringe a liberdade, na definição da estratégia comercial da referida empresa, inclusive na utilização de seus direitos de propriedade intelectual.

Constata-se também o interesse em afastar a aplicação de teorias de origens alheias à tradição europeia, notadamente de matriz norte-americana. Fato que ilustra essa informação é que as Orientações de 2009 só foram publicadas após o julgamento pelos tribunais europeus da Microsoft. Em outras palavras, a Comissão Europeia aguardou os recursos apresentados ao Tribunal Europeu consolidar a modernização.

A precaução da Comissão decorre da preocupação com a confirmação do Tribunal de sua decisão. Consagrou-se também a proteção do interesse do consumidor, por meio da definição do "encerramento do mercado com prejuízo para o consumidor":

No presente documento a expressão «encerramento anticoncorrencial do mercado» é utilizada para designar as situações em que o comportamento da empresa em posição dominante restringe ou impede o acesso efectivo dos concorrentes actuais ou potenciais às fontes de abastecimento ou aos mercados, o que irá provavelmente permitir a esta última aumentar de forma rentável o preço cobrado aos consumidores. A identificação de um prejuizo provável para o consumidor pode basear-se tanto em provas qualitativas como, sempre que possivel e apropriado, em provas quantitativas. A Comissão irá também abordar este tipo de encerramento anticoncorrencial do mercado que cause (provável) prejuizo tanto a nivel intermédio como dos consumidores finais, ou a ambos os niveis (COMISSÃO EUROPEIA, 2009, grifo nosso)

O contexto descrito e a prevalência da proteção do interesse do consumidor ilustram o esforço de construir um conteúdo de origem europeia para as soluções jurídicas contemporâneas. A modernização de 2009 buscou, portanto, atualizar a intervenção do Direito da Concorrência às novas necessidades da Economia, mantendo a sua própria tradição jurídica, política e cultural, formadoras da União Europeia.

Compreende-se que a modernização do Direito da Concorrência da União Europeia colocou em prática a abordagem fundada nos efeitos, inclusive aqueles prováveis, ancorada nos aportes 
contemporâneos da Economia Industria ${ }^{10}$. Logo, o movimento de modernização manteve as características formais da tradição europeia, mas permitiu a avaliação das eficiências das empresas para afastar a lógica da ilicitude per se e aplicar a regra da razão estruturada.

A reforma de 2009 aprofundou o realismo da análise econômica, o que pode enfraquecer a previsibilidade da intervenção das autoridades de concorrência europeias. A referida constatação é ainda mais importante nos casos que tratam dos institutos clássicos de proteção da inovação, como os direitos de propriedade intelectual. Todavia, a sólida jurisprudência europeia permite perceber que muitas empresas de alta tecnologia se utilizam de seu poder de mercado, com a instrumentalização de seus próprios direitos de propriedade intelectual ou de outras estratégias comerciais, para afastar de maneira abusiva outros competidores e outras tecnologias inovadoras.

Além disso, a União Europeia parece estar assumindo uma postura legislativa mais rígida em relação ao mundo digital. O conjunto de regras do Mercado Único Digital (Digital Single Market), que inclui regulamentos, diretivas, estratégias etc., visa a regulamentar o marketing digital, o comércio eletrônico e as telecomunicações na União Europeia. Essa legislação visa a promover transparência para as empresas que utilizam serviços de intermediação online e motores de pesquisa online (UNIÃO EUROPEIA, 2019). De acordo com as definições do regulamento, essas disposições provavelmente se aplicariam à Pesquisa do Google como um mecanismo de pesquisa online (PageRank) e como uma intermediação de serviço online (aplicativos de pesquisa verticais, como o Google Shopping e outras ferramentas de comparação de preços).

Por meio do Regulamento 2019/1150, que se aplica aos buscadores online, por exemplo, é possivel investigar se "a concorrência entre bens ou serviços oferecidos por um usuário empresarial e bens ou serviços oferecidos ou controlados por um prestador de serviços de intermediação online constitui concorrência leal e se os provedores de serviços de intermediação online fazem uso indevido de dados privilegiados a esse respeito" (UNIÃO EUROPEIA, 2019).

As Diretrizes da Comissão Europeia sobre a Transparência de Rankings de acordo com o Regulamento 2019/1150, publicadas em dezembro de 2020, parecem corroborar essa posição, especialmente no que diz respeito às suas disposições de transparência: "os requisitos do artigo 5 aplicam-se aos prestadores de serviços de intermediação online e motores de busca online. Se os fornecedores de motores de busca online estão (vertical ou horizontalmente) integrados, parte do que oferecem também podem ser serviços de intermediação online" (COMISSÃO EUROPEIA, 2020).

Ainda que a Comissão Europeia continue investigando práticas da Google, os três casos analisados neste trabalho culminam em uma regulação bastante minuciosa dessas plataformas. o regulamento parece encapsular aquilo em que os casos contra a Google convergiram ao longo da década: maior transparência para usuários, sejam eles consumidores finais, ou empresas que dependem desse serviço para ter visibilidade nos mercados em que atuam. Segundo o artigo 5o do regulamento

10 “A Economia Industrial, notadamente a partir da década de 1950, trouxe novas percepções sobre o funcionamento do mercado. Esse ramo da economia se desenvolveu a partir do questionamento acerca das críticas aos modelos abstratos ortodoxos, revelando suas imprecisões analíticas. Essas disfunções analíticas prejudicavam a coerência e eficácia na interface entre Estado e mercado, sobretudo, na intervenção da política concorrencial. Todavia, esse ramo da economia não pode ser tratado como um bloco teórico completamente coeso, visto que pelo menos dois grupos de autores são identificáveis. 0 primeiro é a Nova Economia Industrial, que informa o movimento Pós-Chicago. Já o segundo é composto pelos denominados neoschumpeterianos ou evolucionários, notadamente, aqueles vinculados à Economia da Inovação" (LEURQUIN, 2018, p. 278). 
Os provedores de mecanismos de busca online devem estabelecer os parâmetros principais, que individualmente ou coletivamente são mais significativos para determinar a classificação e a importância relativa desses parâmetros principais, fornecendo uma descrição fácil e publicamente disponivel, redigida em linguagem simples e inteligivel, nos mecanismos de busca desses provedores. Essa descrição deve ser mantida atualizada (UNIÃO EUROPEIA, 2019).

Ao tratar da importância do modelo europeu, Tim Wu afirma que a Europa tem liderado o "escrutínio" das grandes empresas de tecnologia. Sendo assim, apesar de não ser um modelo perfeito, sua "disposição para abrir casos importantes quando a concorrência está claramente ameaçada devem servir de modelo para os responsáveis pela aplicação da lei americana e para o resto do mundo"11. A partir dessas constatações, passa-se à análise das condenações europeias da Google.

\section{CONDENAÇÃO NO CASO GOOGLE SHOPPING}

A Comissão Europeia multou a Google em 2,42 bilhões de Euros, em 2017, por ter abusado de sua posição dominante no mercado de motores de busca online, visto que conferiu vantagem ilegal a seu próprio serviço de comparação de preços (PRATIQUES, 2017). Constatou-se que a articulação entre os efeitos de rede e a existência de um mercado de dois lados conferiu peculiaridades ao caso em análise. A avaliação proposta pela Comissão partiu dessas características para punir a autopreferência abusiva em mercado conexo.

O modelo de negócios da Google se baseia na interação entre produtos online, serviços que a empresa oferece gratuitamente e serviços de marketing digital, que geram sua principal fonte de renda. O serviço de pesquisa é utilizado para procurar informações na internet, a partir dos computadores pessoais, laptops, smartphones e tablets. Três resultados podem ser gerados a partir da pesquisa na ferramenta de busca do Google: (i) os resultados "genéricos", também denominados de "orgânicos" ou "naturais"; (ii) os resultados patrocinados (advertising results); e (iii) os resultados especializados (specialised search results) (PRATIQUES, 2017).

É importante notar que essa aparente organicidade das páginas de resultados dos mecanismos de busca da Google é, na verdade, uma suposição errônea pelo público, apesar de largamente difundida entre seus usuários, fruto de uma estratégia altamente eficaz de caracterização de seu modelo de negócio pela própria empresa. Os resultados decorrem de uma combinação entre a matemática referente à relevância algorítmica de certos conteúdos e as decisões editoriais da própria empresa, que, por exemplo, escolhe não mostrar resultados pornográficos, que estimulem violência, que violem conteúdo autoral etc. Ou seja, até mesmo fatores subjetivos influenciam o ranking de resultados no mecanismo de busca.

Os resultados genéricos costumam aparecer no meio da página de resultados da Google,

11 Tradução livre de: "European antitrust is far from perfect, but its leadership and willingness to bring big cases when competition is clearly under threat should serve as a model for American enforcers and for the rest of the world." (WU, 2018, p. 131). 
no formato de links em azul, sutilmente divididos dos resultados patrocinados por uma linha fina. A ordem da apresentação decorre de um processo automático de descoberta de novas e atualizadas páginas, que são indexadas e catalogadas de acordo com seu conteúdo. Em seguida, checa-se a combinação entre a pesquisa realizada pelo usuário e o index da empresa.

A definição da ordem de exposição dos resultados é derivada do algoritmo denominado " $\mathrm{Pa}$ geRank". Em síntese, ele mede a importância de uma determinada página, baseando-se no número e na qualidade de links do sítio, uma vez que a hipótese subjacente é a de que sites mais importantes recebem mais links de outros. A Google utiliza-se de outros mecanismos de ajuste do resultado do "PageRank" com o intuito de melhorar a precisão da pesquisa genérica, porém a empresa não cobra dos sites nenhum pagamento para serem melhor classificados (COMISSÃO EUROPEIA, 2017).

Os resultados patrocinados (advertising results) são anúncios que tipicamente aparecem primeiro nas pesquisas gerais dos usuários da Google, com um rótulo informando aos usuários a sua natureza publicitária. Eles são vinculados à plataforma de publicidade, baseada em leilão da Google (AdWords), que abrange variados tipos de produtos, informações ou serviços (COMISSÃO EUROPEIA, 2017).

A definição dos resultados decorrentes dessa ferramenta é estabelecida a partir de dois elementos principais. o primeiro é a identificação do conjunto relevante de pesquisas patrocinadas a partir da combinação entre as palavras-chaves dos anunciantes e dos usuários. O segundo é a fixação da ordem, a qual depende do valor máximo de preço que o anunciante indicou que pagaria por clique e o índice da qualidade desse anúncio. $O$ índice de qualidade é baseado em alguns critérios, como a taxa de previsão de cliques da pesquisa patrocinada (COMISSÃO EUROPEIA, 2017)

Os resultados especializados decorrem da pesquisa genérica, após a definição de uma categoria particular, uma vez que elementos gráficos e informações dinâmicas costumam chamar atenção dessas especializações, cujos exemplos são o "Google Shopping", "Google Finance", "Google Flights" e "Google Video" (COMISSÃO EUROPEIA, 2017). Alguns serviços da pesquisa especializada são baseados no pagamento para a inclusão dos sites nos seus resultados, como é o caso do Google Shopping:

O modelo de negócios da Google mudou significativamente. A empresa agora apresenta uma ampla variedade de conteúdo proprietário desenvolvido internamente e adquirido em outros lugares, incluindo Google Finance, Google Maps, Google Notícias, Google Travel, Google Flight Search, Google Places, Google Plus, Google Product Search, YouTube e Zagat. Esses serviços executam funções especializadas não intercambiáveis com a função principal de pesquisa da Google e, portanto, existem em mercados de produtos separados (HAZAN, 2013, p. 804).

O Google Shopping é, portanto, um serviço de comparação de preços, cuja primeira versão foi a denominada Froogle, lançada nos EUA, em 2002. A Google mudou o nome dessa plataforma até o ano de 2012, momento no qual a nomenclatura passou a ser a atual, mas houve também uma alteração no modelo do negócio. A partir dessa data, os anunciantes deveriam pagar para viabilizar a sua inclusão nos resultados. Além disso, os resultados dessa busca especializada começaram a aparecer em posicionamento e exibição privilegiados nos resultados genéricos, antes mesmo dos anúncios 
pagos. Essa conduta de autopreferência foi considerada abusiva pela Comissão Europeia.

Também denominada "busca vertical", a incidência de resultados refinados, provenientes de plataformas de pesquisa subjacentes ao mecanismo de busca original, mais especializadas, como é o caso do Google Shopping, impunha preferência no ranqueamento de resultados da própria Google. Dessa forma, a empresa conseguiria (e consegue) dominar mercados em que há serviços mais populares, talvez até mesmo mais eficientes e relevantes para o usuário, em que o mercado de busca e de comparação de preços ou serviços é especializado. Apesar de ter posição dominante no mercado de mecanismos de pesquisa, a Google não o tem (com a mesma intensidade, ao menos) em nichos de pesquisa especializada, onde precisa concorrer com plataformas de notícias, vídeos, comparação de preços de passagens aéreas, hotéis etc.

A Comissão Europeia ancorou a sua análise nas decisões que puniram empresas que buscam estender a sua posição dominante ao mercado conexo, distorcendo a concorrência. A decisão Google Shopping se filia ao percurso jurisprudencial que remonta ao caso Compagnie Luxembourgeoise de Télédiffusion (1985), ao caso Tetra Park (1996), ao caso Irish Sugar (1998) e ao caso Microsoft (2007).

A definição desse percurso definiu o quadro de análise adotado pela Comissão Europeia, composto por três condições: (i) a constatação da posição dominante; (ii) a existência de dois mercados e sua conexão; e (iii) a verificação da restrição da concorrência. A primeira etapa foi a mais simples de se constatar, pois a Comissão identificou que a Google tem desfrutado posição dominante nos mercados de pesquisa genérica em todos os mercados dos países europeus desde 2008. A única exceção foi a República Checa, cuja posição dominante foi adquirida somente em 2011.

Outro fator relevante para reforçar a posição dominante do Google são as barreiras à entrada muito elevadas, devido aos efeitos de rede. Em outros termos, o fato de haver cada vez mais usuários utilizando o motor de busca da Google torna-o ainda mais atrativo aos anunciantes, bem como possibilita um aperfeiçoamento cada vez maior de suas sugestões publicitárias ${ }^{12}$. Além disso, é dificil atingir a mesma escala computacional de "varredura de informações" (web crawling, que consiste na análise e indexação de informações de toda a internet) que a Google possui atualmente. Os lucros decorrentes desse processo, por sua vez, são utilizados para atrair ainda mais consumidores por meio do desenvolvimento de aplicações conexas da Google, ofertadas em geral gratuitamente. Ademais, os dados colhidos dos consumidores também são utilizados para refinar ainda mais os resultados de pesquisa (STATEMENT..., 2017).

A constatação da existência de dois mercados e de sua conexão exigiu maior esforço na argumentação da Comissão Europeia, essencialmente no que diz respeito à distinção entre o mercado de comparação de preços e o de pesquisa genérica. A compreensão da sua decisão deve partir do conceito de mercado de dois lados. De acordo com Jean Tirole, é um:

[...] modelo do "mercado de dois lados", isto é um mercado no qual um in-

12 O fato de que a plataforma de busca é utilizada em larga escala faz com que a empresa tenha a habilidade de aperfeiçoar seus sistemas de perfilamento de preferências dos usuários, e, por consequência, fazer anúncios mais eficientes (que se convertem em mais cliques). O feedback de cada anúncio, seja ele clicado ou não, gera métricas minuciosas, a partir de uma ampla base de dados de análise, que, por sua vez, podem ser transformadas em aperfeiçoamento das estratégias futuras de campanha publicitária (O’NEIL, 2016, p. 75). 
termediário (e seu proprietário, Visa, Sony, Google, Facebook, agência imobiliária) permite aos vendedores e compradores interagir. Essas "plataformas" reúnem múltiplas comunidades de utilizadores que procuram interagir umas com as outras: por exemplo, os jogadores e desenvolvedores de jogos no caso da indústria de jogos de videogame; os utilizadores dos sistemas operacionais (Windows, Android, Linux, OS X do seu Mac ou iOS de seu IPhone) e os desenvolvedores de aplicativos no domínio dos sistemas operacionais; os utilizadores e anunciantes nos casos de motores de busca ou das mídias; os detentores de cartões bancários e seus comerciantes nos casos de transação por cartão (TIROLE, 2016, p. 499)13.

O mercado de dois lados é um arranjo que vincula duas pontas, no qual um lado apenas se valoriza com o crescimento e a expansão do outro. Esse modelo está no centro da dinâmica da economia digital, mas a sua origem remonta a formatos mais antigos, como os cartões de crédito e os anúncios nas mídias. Uma de suas características mais importantes para a aplicação do Direito da Concorrência é que um dos lados do mercado costuma ter preços muito baixos e, por vezes, nulos.

No caso em espécie, existe uma falsa percepção de que os usuários da Google não pagam pelas pesquisas realizadas em seus motores de busca. Segundo Vestager:

Consumidores utilizam ferramentas de pesquisa que produzem resultados incrivelmente precisos. Redes sociais permitem às pessoas manter contato com amigos, onde quer que estejam no mundo. E eles não pagam um centavo por esses serviços. Em vez disso, eles pagam com seus dados. Isso não precisa ser um problema, desde que as pessoas estejam felizes que seus dados que compartilham tenham um preço justo, para pagar os serviços que eles obtêm em troca. Dados pessoais tornaram-se uma mercadoria valiosa (VESTAGER, 2016) ${ }^{14}$.

A utilização de dados pessoais representa um valor mercadológico. Cumpre frisar que algumas empresas pagam para manter os dados dos utilizadores, como o aplicativo Screenwise Trends Panel e a empresa Handshake. Petit (2016, p. 6) analisa caso fictício, similar às questões concorrenciais decorrentes das estratégias da Google, e entende que se trata de "mercado de compra em natura dos resultados da pesquisa genérica dos internautas".

13 Tradução livre do original: “[...] modèle du «marché biface», c'est-à-dire un marché où un intermédiaire (et son propriétaire, Visa, Sony, Google, Facebook, l'agence immobilière) permet à des vendeurs et des acheteurs d'interagir. Ces «plates-formes» rassemblent de multiples communautés d'utilisateurs qui cherchent à interagir les unes avec les autres: par exemple, les joueurs et les développeurs de jeux dans le cas de l'industrie du jeu vidéo; les utilisateurs de systèmes d'exploitation (Windows, Android, Linux, l'OS X de votre Mac ou iOS de votre iPhone) et les développeurs d'applications dans le domaine des systèmes d'exploitation ; les utilisateurs et les annonceurs dans le cas des moteurs de recherche ou des médias; les détenteurs de carte bancaire et les commerçants dans le cas de transactions par carte de paiement" (TIROLE, 2016, p. 499).

14 Tradução livre do original: "Consumers use search engines that produce incredibly accurate results. Social networks let people keep in touch with friends, wherever they are in the world. And they don't pay a single penny for those services. Instead, they pay with their data. That doesn't have to be a problem, as long as people are happy that the data they share is a fair price to pay for the services they get in return. Personal data has become a valuable commodity" (VESTAGER, 2016). 
A conexão entre os dois mercados se estabelece a partir do próprio conceito de mercado de dois lados, visto que o mercado publicitário só se justifica se há mais utilizadores do lado gratuito. Deve-se salientar que há autonomia do mercado de comparadores de preços em relação à pesquisa genérica. Essa constatação decorre também pelo fato de o modelo de negócio, os algoritmos e seus mecanismos de ajustes serem distintos.

A última etapa do quadro de análise é a constatação das restrições à concorrência. A Comissão entendeu que os mercados nacionais de serviços de comparação de preços sofreram efeitos anticoncorrenciais e decorrem da possibilidade de exclusão dos serviços de comparação de compras concorrentes, o que pode elevar os custos para os comerciantes, aumentar o preço para os consumidores e reduzir a inovação. De acordo com a Comissão Europeia:

[...] é provável que a conduta reduza os incentivos dos serviços de comparação de preços concorrentes para inovar. Serviços de comparação de preços terão incentivo para investir no desenvolvimento de serviços inovadores, melhorando a relevância de seus serviços existentes e criando novos tipos de serviços, apenas se eles puderem razoavelmente esperar que seus serviços sejam capazes de atrair volume suficiente de tráfego de usuário para competir com o serviço de comparação de preços do Google. Além disso, mesmo que os serviços de comparação de preços concorrentes possam tentar compensar até certo ponto a diminuição do tráfego, dependendo mais em fontes pagas de tráfego, isso também reduzirá a receita disponível para investir no desenvolvimento de serviços inovadores ${ }^{15}$.

A Comissão também entendeu que a conduta provavelmente reduz a habilidade do consumidor de acessar a maioria dos serviços de comparação de compras relevantes. Essa análise decorreu da consideração do fato de que os usuários tendem a considerar os resultados da pesquisa genérica como os mais relevantes para as suas necessidades, mesmo se os outros resultados forem mais adequados (UNIÃO EUROPEIA, 2007).

O conceito de relevância não é uniforme, bem como está sujeito a uma miríade de subjetividades. Inclusive, é justamente a capacidade de entender o que é "relevante" para cada usuário o modelo de negócio da ferramenta de buscas da Google. Resultados universais, que não fossem personalizados, ou que não oferecessem uma curadoria especial, seriam considerados semelhantes aos de uma lista telefônica digital, ou de URLs (HAZAN, 2013, p. 813). No entanto, quando se analisa a interação do serviço principal de buscas, com as buscas verticais, entende-se que o conceito de relevância comparativa entre as aplicações especializadas nem chega a ser apresentado como opção para o usuário, o que reforça a importância auto-sugestiva da plataforma em relação a suas próprias

15 Tradução livre do original: “[...] the Conduct is likely to reduce the incentives of competing comparison shopping services to innovate. Competing comparison shopping services will have an incentive to invest in developing innovative services, improving the relevance of their existing services and creating new types of services, only if they can reasonably expect that their services will be able to attract a sufficient volume of user traffic to compete with Google's comparison shopping service. Moreover, even if competing comparison shopping services may try to compensate to some extent the decrease in traffic by relying more on paid sources of traffic, this will also reduce the revenue available to invest in developing innovative services" (UNIÃO EUROPEIA 2007). 
aplicações.

Além disso, a Google não informa a seus usuários que o produto é posicionado, na pesquisa genérica, a partir de mecanismos diferentes para estabelecer a ordem de exibição (UNIÃO EUROPEIA, 2007). Dessa forma, a Comissão Europeia concluiu que essa conduta não era compatível com a competição pelos méritos, visto que ela conduziu o tráfego da pesquisa genérica em direção às plataformas de comparação de preços. Além disso, esse procedimento privilegiou o tráfego no Google Shopping, causando danos aos demais concorrentes nesse outro mercado.

As análises da Comissão também permitiram deduzir que, entre 2011 e 2016, houve aumento do tráfego no Google Shopping; redução nos de seus concorrentes; e manutenção nas plataformas dos comerciantes. Cumpre destacar que essa data é convergente com a extensão do algoritmo Panda, a partir dos anos 2011, que contribuiu à redução significativa da visibilidade de competidores de comparação de preço na pesquisa genérica da Google (UNIÃO EUROPEIA, 2007).

A Comissão ainda compreendeu que a autopromoção de serviço de comparação de preço da Google garante proteção de parte dos retornos gerados por sua própria pesquisa genérica (UNIÃO EUROPEIA, 2007). Esse aporte financeiro reforça a posição dominante do serviço de pesquisa genérica da Google, o que dificulta artificialmente a concorrência.

A Comissária Margrethe Vestager afirmou que a conduta da Google foi ilegal, conforme as normas do Direito da Concorrência da União Europeia, pois a empresa negou a chance de as demais competirem pelos seus próprios méritos e de inovar. Além disso, ela impediu que consumidores europeus usufruíssem dos beneficios da concorrência, impedindo-os de escolher os serviços e as inovações. De acordo com a responsável pela concorrência na Comissão Europeia:

o que isso significa na prática? Imagine, você quer procurar um produto online. Você digita esse produto na ferramenta de pesquisa da Google. 0 que você vai ver no topo da página é uma caixa com o resultado do Google Shopping, com uma foto e uma seleção de compras de diferentes vendedores. Eles estão localizados acima dos resultados genéricos que o algoritmo genérico da Google considera mais relevante. Isso acontece sempre que a Google quiser apresentar resultados de comparação de preços em resposta a uma consulta de pesquisa. Algumas vezes, os resultados de comparação de preços de rivais são rejeitados em seus resultados de pesquisa. As evidências mostram que mesmo o rival melhor classificado aparece, em média, apenas na quarta página de resultados do Google. Outros aparecem ainda mais para baixo (STATEMENT, 2017) ${ }^{16}$.

16 Tradução livre do original: “So, what does this mean in practice? Imagine, you want to look for a product online. You type the product into the Google search engine. What you will see right at the top of the page is a box with Google Shopping's results, with pictures and a selection of deals from different retailers. They are placed above the results that Google's generic search algorithms consider most relevant. This happens whenever Google wants to present comparison shopping results in response to a search query. Sometimes, results are also displayed in a reserved place on the right-hand side. At the same time, Google has demoted rival comparison shopping services in its search results. The evidence shows that even the most highly ranked rival appears on average only on page four of Google's search results. Others appear even further down" (STATEMENT, 2017). 
Os serviços do Google Shopping se inserem em uma dinâmica econômica caracterizada por curtos ciclos de inovação. Grandes parcelas de mercado podem se tornar efêmeras e podem não indicar, obrigatoriamente, uma posição dominante. A Comissão não excluiu a possibilidade de aplicar o Direito da Concorrência nesse tipo de caso, em especial o art. 102, do Tratado sobre o Funcionamento da União Europeia (TFUE) (UNIÃO EUROPEIA, 2016). Essa compreensão é reforçada ao perceber que o rápido crescimento de mercado não demonstra sinais de instabilidade durante o período em análise, conforme o caso em questão, que revelou hierarquia bastante estável.

Deste modo, constata-se que a decisão da Google Shopping se soma à da Microsoft no sentido de estabelecer com mais precisão a possibilidade de as normas de Direito da Concorrência serem aplicadas para a proteção da inovação. Essa proteção decorre de um exercício de avaliação sobre quem tem maior interesse em inovar, em um determinado mercado relevante: a empresa que abusa da sua posição dominante ou suas concorrentes.

\section{CONDENAÇÃO NO CASO GOOGLE-ANDROID}

A Comissão Europeia aplicou uma multa de 4,34 bilhões de Euros à Google, em julho de 2018, por ter abusado da posição dominante no motor de busca relacionado a sistemas operacionais Android. De acordo com Margrethe Vestager, as práticas da Google privaram seus concorrentes da possibilidade de inovar e de competir pelos seus próprios méritos (STATEMENT..., 2018). o caso trata de práticas anticoncorrenciais concebidas no momento da passagem do computador fixo à internet móvel, o que alterou substancialmente a dinâmica do setor. A Comissão concluiu que a Google tem uma posição dominante nos mercados de serviços de pesquisa genérica na internet, no mercado de sistemas operacionais nos smartphones sob licença e no das lojas de aplicação em linha para o sistema.

Sobre o primeiro mercado, a decisão da Comissão no caso Google Shopping já avaliou suficientemente a posição dominante da empresa, como visto anteriormente. No que diz respeito ao segundo mercado, tem-se que frisar que os fabricantes de smartphone podem fazer funcionar o sistema Android, sob licença, em seus aparelhos. É importante ressaltar que esse mercado é caracterizado por altas barreiras à entrada, sobretudo por causa dos efeitos de rede, visto que a quantidade de consumidores do sistema de exploração aumenta a quantidade de desenvolvedores de aplicativos para esse sistema, permitindo integrar mais utilizadores. A Comissão estimou uma parte de mercado de mais de 95\%, excetuando a China. No que diz respeito ao terceiro mercado, a Comissão indicou que mais de $90 \%$ dos aplicativos baixados nos aparelhos Android são via Play Store. Esse mercado é igualmente caracterizado pelas altas barreiras à entrada, igualmente por causa dos efeitos de rede.

A Comissão puniu a Google por três tipos de restrição: venda casada dos aplicativos de pesquisa e de navegação da Google; pagamentos ilegais subordinados à pré-instalação exclusiva de Google Search; e obstrução do desenvolvimento e da distribuição de sistemas operacional Android concorrentes.

A licença da Google engloba o Google Play Store, o aplicativo Google Search e o navegador Google Chrome. O Play Store é um aplicativo indispensável, pois os utilizadores esperam tê-lo pré- 
-instalado, não podendo baixá-lo legalmente. A Comissão concluiu que ficou caracterizada a venda casada do aplicativo Google Search e do navegador Google Chrome. O objetivo de pré-instalar esses dois aplicativos foi o de conduzir, de maneira artificial, a utilização desses aplicativos de pesquisa e de navegação. Além disso, a empresa estipulou as licenças dos produtos Google, excluindo a possibilidade de haver outros aplicativos pré-instalados e reduzindo a possibilidade que outros concorrentes possam entrar no mercado em questão.

De acordo com a Comissão, a Google pagou a alguns dos maiores fabricantes de aparelhos Android, assim como a operadores de redes móveis, para ter exclusividade na pré-instalação do Google Search. Essa prática trouxe prejuizo à concorrência, pois reduziu os estímulos a pré-instalar aplicativos de pesquisa concorrentes.

A Comissão constatou ainda que a Google impedia que fabricantes de aparelhos utilizassem a "forks Android", uma outra versão não aprovada pela empresa em espécie. De acordo com a Comissão:

Como consequência, o comportamento da Google teve incidência direta sob os utilizadores, na medida em que ele os impediu de acessar a novas inovações e a smartphone baseados em outras versões do sistema operacional Android. Em outros termos, por causa dessa prática, é a Google - e não os utilizadores, os desenvolvedores de aplicativos e o mercado - que determinava efetivamente os sistemas operacionais suscetiveis de serem coroados com sucesSo (COMISSÃO EUROPEIA, 2018).

É possivel concluir que a estratégia da Google impediu que outros motores de pesquisa concorrentes pudessem entrar no mercado, dificultando o desenvolvimento técnico, notadamente no que diz respeito ao "forks Android". Além disso, esses abusos obstaram que outros motores de pesquisa coletassem dados provenientes dos smartphones, o que consolidou artificialmente a posição dominante da Google. Dessa forma, a Comissão reforçou a centralidade da interoperabilidade ao incorporar a proteção da inovação na sua abordagem.

\section{CONDENAÇÃO NO CASO GOOGLE ADSENSE}

A Comissão da União Europeia multou a Google em 1,49 bilhões de Euros, em março de 2019, por suas práticas abusivas no uso da posição dominante na intermediação de publicidade em mecanismos de busca. A empresa foi considerada culpada por impor obrigações de fornecimento exclusivo, estipulando onde os resultados de pesquisa mais lucrativos deveriam ser exibidos e reservando esses espaços para seus próprios anúncios. De acordo com a Comissão Europeia:

Essas cláusulas restritivas levam a um círculo vicioso. Os rivais da Google não conseguiram crescer e competir. Como resultado, os proprietários de sites tinham opções limitadas para vender espaço publicitário nesses sites e eram forçados a confiar exclusivamente na Google. E, como resultado disso, a Google se beneficiou dos efeitos de rede e se tornou ainda mais forte. Não havia motivo para a Google incluir essas cláusulas restritivas em seus 
contratos, exceto para manter seus rivais fora do mercado. É por isso que concluímos que, entre 2006 e 2016, o comportamento da Google foi ilegal de acordo com as regras antitruste da UE. Impediu que seus rivais tivessem a chance de inovar e competir com base nos méritos. Anunciantes e proprietários de sites tinham menos escolha e provavelmente enfrentavam preços mais altos, que seriam repassados aos consumidores (STATEMENT..., 2019)17.

Em termos gerais, a Comissão Europeia entendeu que "a Google criou um modelo de negócios que obtém lucros apenas quando os consumidores selecionam anúncios pagos em vez de resultados orgânicos". Esse modelo de negócio, embora ainda produza muito bem-estar para o consumidor, é capaz de prejudicar os interesses dos usuários e fornecedores, principalmente no caso de manipulação dos resultados da pesquisa. Como as autoridades de concorrência europeias e americanas descobriram, classificações manipuladas podem causar discriminação de preços e aumento artificial dos custos de publicidade, uma limitação do acesso dos usuários a informações sobre determinados provedores e, consequentemente, uma redução na variedade de mercado.

Ainda que a busca da Google possa ser tão eficiente como uma ferramenta online para comparação e acesso a uma lista relevante de provedores, a criação de suas estratégias de monetização tornou seu modelo de negócios potencialmente prejudicial aos consumidores. 0 algoritmo da Google está no centro deste problema, porque uma explicação para seu processo de tomada de decisão (ou a falta de explicação) pode determinar a necessidade de regulação adicional. "Embora o serviço que a Google oferece facilite inerentemente a atividade econômica, ele tem a capacidade e o incentivo de obstruir essa atividade e prejudicar os consumidores em relação a um mecanismo de pesquisa que obteve lucros de forma diferente".

Sabe-se que a Google tem uma posição dominante no negócio de pesquisas online (mercado primário), embora esse possa não ser o caso de seu negócio de pesquisa vertical (mercado secundário conexo). Ao exercer esse poder em seu mercado primário, "a Google se tornou um gargalo para o fluxo de informações na internet e [...] explorou esse poder para direcionar desproporcionalmente os usuários para o próprio conteúdo da Google." O mesmo raciocínio do modelo de negócios pode ser encontrado na exportação dessa estratégia para seu sistema operacional (Android) e suas ferramentas de intermediação publicitária (AdSense).

É importante destacar que essa condenação só foi possivel pela compreensão, cada vez mais apurada, do modelo de negócios da Google. A interpretação das atividades econômicas da empresa abriu margem para os concorrentes afetados reivindicarem indenizações em ações civis perante os tribunais dos Estados membros da União Europeia.

Neste caso, por exemplo, as investigações decorreram de relatos de que a empresa estava

17 Tradução livre de: "These restrictive clauses lead to a vicious circle. Google's rivals were unable to grow and compete. As a result, owners of websites had limited options for selling advertising space on these websites and were forced to rely solely on Google. And, as a result of that, Google benefited from network effects and became even stronger. There was no reason for Google to include these restrictive clauses in its contracts, except to keep its rivals out of the market. This is why we've concluded that, between 2006 and 2016, Google's behaviour was illegal under EU antitrust rules. It prevented its rivals from having the chance to innovate and compete on the merits. Advertisers and website owners had less choice and likely faced higher prices, that would be passed on to consumers." (STATEMENT..., 2019). 
abusando de sua posição dominante ao restringir as opções de anúncios em busca de sites de terceiros à Google, sufocando a concorrência. Os contratos de intermediação de publicidade em pesquisas estavam disponiveis para análise das autoridades de concorrência e foi possivel constatar que algumas de suas cláusulas eram abusivas. Além disso, todas essas investigações revelaram o modus operandi da Google em relação ao seu algoritmo de busca, tendo em vista que os contratos de intermediação de publicidade em busca estavam disponiveis para que as autoridades de concorrência examinassem e considerassem as suas cláusulas.

Foi possivel confirmar que o mercado de intermediação de publicidade de busca é composto por uma ferramenta de busca no site de varejistas, operadoras de telecomunicações e jornais, entre outros. Ao inserir uma consulta, os usuários são expostos não apenas a resultados não pagos, mas também a anúncios de busca intermediados pela Google ou por seus concorrentes, que recebem uma comissão por clique.

De forma semelhante ao mercado de mecanismos de busca, a Google detinha $80 \%$ do mercado europeu de intermediação de publicidade em buscas na época. Para os proprietários de sites terceirizados aos quais a Google forneceu esses serviços, havia preocupações com relação às cláusulas de exclusividade contratual, colocação premium de um número mínimo de anúncios de pesquisa da Google e o direito de autorizar (ou não) anúncios concorrentes. Essas práticas teriam durado mais de dez anos.

A Google tem um negócio bem estabelecido e bem-sucedido, que é seu mecanismo de busca. Nesse mercado relevante, em várias jurisdições, a Google tem uma posição dominante. No entanto, a pesquisa online é uma ferramenta ampla que engloba também mecanismos de pesquisa vertical, ou seja, ferramentas de classificação e pesquisa especializadas, como pesquisa de imagens, voos, mapas, vídeos etc. abre portas para outros aplicativos de pesquisa vertical, que geralmente recebem um tratamento preferencial ao serem classificados em uma página de resultados. Mesmo que a Google Flights não seja a melhor e mais eficiente ferramenta de comparação de preços para passagens aéreas neste mercado em particular, onde empresas como a Kayak e a Submarino podem ser os mais eficientes, por exemplo, é aquele que a Google escolhe exibir em uma consulta de voos em seu mecanismo de pesquisa, no qual é definitivamente um líder.

A Comissão Europeia entendeu que esses comportamentos podem prejudicar a inovação e reduzir a escolha de empresas que contratam publicidade online, devido ao fato de que os concorrentes dificilmente teriam escolha para competir, inclusive com novos modelos de negócios, e os preços seriam principalmente definidos pela Google. O domínio do mercado não constitui inerentemente um problema de concorrência ao abrigo da legislação da União Europeia. No entanto, um abuso dessa posição, por meio de tais práticas, por exemplo, maximiza o tráfego de seus próprios anúncios em mecanismos de busca e limita a capacidade de concorrentes, como Yahoo e Microsoft, de colocar anúncios em mecanismos de busca de sites de terceiros.

\section{CONCLUSÃO}

O Direito da Concorrência não pode ser tratado como a solução para todos os problemas jurídicos e econômicos que caracterizam a sociedade de informação contemporânea. Entretanto, 
esse ramo do Direito, sobretudo como vem sendo aplicado na União Europeia, pode ser considerado essencial na consolidação de estruturas econômicas mais conducentes à inovação.

Conforme elucidado, a avaliação dos potenciais danos à inovação causados por esses monopólios da sociedade de informação tem estado no topo da agenda da Comissão Europeia, especialmente a partir da histórica condenação contra a Microsoft. Portanto, a análise das condenações permite concluir que elas corroboram a aplicação dos argumentos empregados na modernização do eixo das práticas unilaterais.

O fato de a União Europeia ter adotado o Regulamento n. 1150 em 2019 reforça a regulação setorial ex ante das práticas de plataformas semelhantes à Google. A busca por maior transparência nesses mercados que envolvem a utilização de algoritmos proprietários está presente em toda a norma e incorpora diversas soluções propostas nos três casos aqui analisados. Além disso, o regulamento estabelece critérios que evidenciam os principais parâmetros para ranqueamento e demoção de resultados em suas plataformas, buscando-se, portanto, ambientes digitais de maior simetria de informações e concorrência.

Este trabalho também permite entender que a aplicação do Direito da Concorrência serve para os seus propósitos clássicos, ou seja, mitigar condutas anticoncorrenciais e quebrar monopólios. Isto é, esse ramo do Direito também tem, a partir do controle do poder privado, desdobramentos em outras dimensões essenciais em um regime democrático. As preocupações decorrentes do tratamento de dados são um exemplo de outras camadas de importância da aplicação do Direito da Concorrência.

Essas outras funções regulatórias têm se perdido nas últimas décadas, principalmente, no que diz respeito à indústria de tecnologia. O relaxamento na aplicação do Direito da Concorrência, por exemplo, ocorreu sobretudo por causa da redução efetiva dos preços aos consumidores, ou mesmo pelo oferecimento de serviços "de graça". Em outras palavras, as abordagens simplificadas de bem-estar do consumidor permitiram que as normas jurídicas reforçassem as falácias do inevitabilismo tecnológico. 0 modelo europeu vem na contramão dessa tendência, revelando uma série de potencialidades do Direito da Concorrência e revigorando a importância das autoridades de defesa pela concorrência na Europa, mas também em outros países.

\section{REFERÊNCIAS}

THE 100 LARGEST companies in the world by market capitalization in 2020. Statista, maio 2020. Disponivel em: https:// bit.ly/32A1hV2. Acesso em: 6 jan. 2021.

ANG, Carmen. The Economic Impact of COVID-19, According to Business Leaders. Markets Insider, 29 dez. 2020. Disponivel em: https:// bit.ly/3aqPBIL. Acesso em: 6 jan. 2021.

ANTITRUST: Commission fines Google €1.49 billion for abusive practices in online advertising. Comissão Europeia, 20 mar. 2019. Disponivel em: https:// bit.ly/3ashtvz. Acesso em: 06 jan. 2021.

BRASIL. Conselho Administrativo de Defesa Econômica (Cade). Inquérito Administrativo no 08700.003211/2016-94. Interessados: YELP, INC., Google Inc., Google Inc., Google Brasil Ltda., José Del Chiaro Ferriera da Rosa. 20 abr. 2016. Disponivel em: https:// bit.ly/2RQRkkf. Acesso em: 21 jan. 2021. 
BRASIL. Conselho Administrativo de Defesa Econômica (Cade). Inquérito Administrativo no 08700.003498/2019-03. Interessados: Google Inc., Google Brasil Ltda. 08 jun. 2019. Disponivel em: https:// bit.ly/3x8Ymkv. Acesso em: 21 jan. 2021.

CHRISTENSSON, Per. Cookie Definition. TechTerms, 9 jul. 2011. Disponivel em: https:// bit.ly/32y4a8U. Acesso em: 21 jan. 2021.

COMISSÃO EUROPEIA. Antitrust Cartel Cases: 39740 Google Search (Shopping). 27 jun. 2017. Disponivel em: https:// bit.ly/3dBy2HK. Acesso em: 23 dez. 2020.

COMISSÃO EUROPEIA. Comunicação da Comissão - Orientação sobre as prioridades da Comissão na aplicação do artigo 82. do Tratado CE a comportamentos de exclusão abusivos por parte de empresas em posição dominante. 24 fev. 2009. Disponivel em: https:/ / bit.ly/32tL1Fe. Acesso em: 20 jan. 2021.

COMISSÃO EUROPEIA. Guidelines on Ranking Transparency Pursuant to Regulation (EU) 2019/1150. 4 dez. 2020. Disponivel em: https:// bit.ly/3sCuMAl. Acesso em: 20 jan. 2021.

COY, Peter. The Secret To Google's Success. Bloomberg Businessweek, 6 mar. 2006. Disponivel em: https://bloom.bg/3gqPPDx. Acesso em: 5 jan. 2021.

ESTADOS UNIDOS. Departmente of Justice (DOJ). Justice Department Sues Monopolist Google For Violating Antitrust Laws: Department Files Complaint Against Google to Restore Competition in Search and Search Advertising Markets. Washington, DC: Office of Public Affairs of the Department of Justice, 2020. Disponivel em: https:// bit.ly/2QlWMei. Acesso em: 7 jan. 2021.

HAZAN, Joshua G. Stop Being Evil: A Proposal For Unbiased Google Search. Michigan Law Review, v. 111, n. 5, mar. 2013. Disponivel em: https:// bit.ly/3v1P2wX. Acesso em: 4 jan. 2021.

KANG, Cecilia; MCCABE, David; WAKABAYASHI, Daisuke, U.S. Accuses Google of Illegally Protecting Monopoly. The New York Times, 20 out. 2020. Disponivel em: https://nyti.ms/3xlwTw6. Acesso em: 20 jan. 2021.

LEURQUIN, Pablo Georges Cícero Fraga. Proteção da inovação pelo Direito Brasileiro da Concorrência e diálogo com o Direito da União Europeia. 2018. Tese (Doutorado) - Universidade Federal de Minas Gerais, Belo Horizonte, 2018. Disponivel em: https:/ / bit.ly/3elGNoy. Acesso em: 22 jan. 2021.

MOROZOV, Evgeny. Big Tech: a ascensão dos dados e a morte da política. São Paulo: Ubu Editora, 2018. O'NEIL, Cathy. Weapons of Math Destruction: How Big Data Increases Inequality and Threatens Democracy. New York: Crown Publishers, 2016.

PETIT, Nicolas. Droit de l'UE (Partie I). In: L'application du droit de la concurrence au secteur numérique. Nanterre: Concurrences, 2016. Disponivel em: https://bit.ly/3dzT7mc. Acesso em: 20 dez. 2020.

PRATIQUES anticoncurrentielles: la Commission inflige à Google une amende de 2,42 milliards d'euros pour abus de position dominante sur le marché des moteurs de recherche en favorisant son propre service de comparaison de prix. Comissão Europeia, 27 jun. 2017. Disponivel em: https:/ / bit.ly/3nfJSLf. Acesso em: 10 jan. 2021.

PRIETO, Catherine. Notion d'abus: Comparaisons transatlantiques dans les affaires Microsoft. Concurrences Review, n. 1, 2004. Disponivel em: https:// bit.ly/2QGX27s. Acesso em: 20 dez. 2020. 
PRIETO, Catherine; BOSCO, David. Droit européen de la concurrence: ententes et abus de position dominante. Bruxelas: Bruylant, 2013.

RODRIGUES, Lorenna. Investigado pelos EUA, Google é alvo de três processos no Cade. Estado de São Paulo, 22 out. 2020. Disponivel em: https:/ / bit.ly/2QGXClE. Acesso em: 07 jan. 2020.

STATEMENT by Commissioner Vestager on Commission Decision to Fine Google $€ 1.49$ Billion for Abusive Practices in Online Advertising. Press release, 20 mar. 2019b. Disponivel em: https://bit.ly/3arfTKX. Acesso em: 12 jan. 2021.

STATEMENT by Commissioner Vestager on Commission decision to fine Google $€ 2.42$ billion for abusing dominance as search engine by giving illegal advantage to own comparison shopping service. Comissão Europeia, 29 jun. 2017. Disponível em: https:// bit.ly/3suzAYs. Acesso em: 10 jan. 2021.

STATEMENT by Commissioner Vestager on Commission decision to fine Google €4.34 billion for illegal practices regarding Android mobile devices to strengthen dominance of Google's search engine. Comissão Europeia, 18 jul. 2018. Disponivel em: https:// bit.ly/2QKAAu8. Acesso em: 10 jan. 2021.

STERLING, Greg. Survey: Amazon beats Google as starting point for product search. Search Engine Land, 28 jun. 2016. Disponivel em: https:/ / bit.ly/3tzkeTO. Acesso em: 6 jan. 2021.

TIROLE, Jean. Économie du bien commun. Paris: PUF, 2016.

UNIÃO EUROPEIA. Regulation (EU) 2019/1150 of the European Parliament and of the Council of 20 June 2019 on Promoting Fairness and Transparency for Business Users of Online Intermediation Services. Luxemburgo: União Europeia, 2019. Disponivel em: https:// bit.ly/2QGZF9k. Acesso em: 20 jan. 2020.

UNIÃO EUROPEIA. Tratado de Funcionamento da União Europeia. Luxemburgo: União Europeia, 2016. Disponivel em: https:// bit.ly/32w8R3d. Acesso em: 12 jan. 2021.

UNIÃO EUROPEIA. Tribunal de Primeira Instância das Comunidades Europeias. Processo n. T- 201/04. Microsoft Corp. v Commission of the European Communities. Luxemburgo: União Europeia, 2007. Disponivel em: https:// bit.ly/2QEfCgD. Acesso em: 20 set. 2020.

VALENTE, Jonas. Cade investiga prática anticompetitiva do Google. Agência Brasil, 12 jun. 2019. Disponivel em: https:// bit.ly/32wKRx2. Acesso em: 21 jan. 2021.

VESTAGER, Margrethe. Making data work for us. European Commission, 9 set. 2016. Disponivel em: https:/ / bit.ly/3svy3kN. Acesso em: 21 jan. 2021

WACHTER, Sandra. Data Protection in the Age of Big Data. Nature Electronics, v. 2, 2019. Disponivel em: https://doi.org/10.1038/s41928-018-0193-y. Acesso em: 22 dez. 2020.

WALSH, James D. A Small Target in a Big Case: Scott Galloway on the antitrust case against Google. Intelligencer, 2 nov. 2020. Disponivel em: https://nym.ag/32wOlzC. Acesso em: 7 jan. 2021.

WU, Tim. The curse of bigness: antitrust in the new gilded age. New York: Columbia Global Reports, 2018.

ZUBOFF, Shoshana. The Age of Surveillance Capitalism. New York: Profile Books Ltd., 2019.BRASIL. 